Research Article

\title{
Experimental Study on Mechanical Properties of Fly Ash Stabilized with Cement
}

\author{
Shengquan Zhou, ${ }^{1}$ Yongfei Zhang $\mathbb{D},{ }^{1}$ Dawei Zhou, ${ }^{1}$ Weijian Wang, ${ }^{1}$ Dongwei Li, ${ }^{2}$ \\ and Zhaibang $\mathrm{Ke}^{3}$ \\ ${ }^{1}$ School of Civil Engineering and Architecture, Anhui University of Science and Technology, Huainan 232001, China \\ ${ }^{2}$ School of Civil and Architectural Engineering, East China University of Technology, Nanchang 330013, China \\ ${ }^{3}$ Anhui Key Laboratory of Green Building and Assembly Construction, Hefei 230032, China
}

Correspondence should be addressed to Yongfei Zhang; 1392324734@qq.com

Received 25 December 2019; Revised 25 June 2020; Accepted 23 August 2020; Published 2 September 2020

Academic Editor: Hui Yao

Copyright (c) 2020 Shengquan Zhou et al. This is an open access article distributed under the Creative Commons Attribution License, which permits unrestricted use, distribution, and reproduction in any medium, provided the original work is properly cited.

\begin{abstract}
Cement-fly ash mixture has been commonly used for the foundation treatment projects in the fly ash stratum, as it is effective in improving foundation bearing capacity and reducing settlement of stratum. In order to figure out the effect of dynamic and static load on the mechanical properties exhibited by the cement-fly ash and the reaction mechanism of cement-fly ash, a combination of the unconfined compressive test, impact test, scanning electron microscopy (SEM), and X-ray diffraction (XRD) method was adopted in this study to investigate the cement-fly ash test samples. As demonstrated by the results, the observed growth rate of 0-60 days $(\mathrm{d})$ is higher than that in the later stages and the typical stress-strain curve can be divided into six sections under the unconfined compressive test. At the gas pressure of $0.2 \mathrm{MPa}$, the cement-fly ash samples exhibited obvious plastic properties in early curing time $(0-60 \mathrm{~d})$, and brittle failure was observed in the final stage $(90 \mathrm{~d})$. It is obvious that the value of dynamic compressive strength (DCS) is higher than that of unconfined compressive strength (UCS). The analysis of XRD has revealed that the hydration products are primarily derived from the hydration reaction of cement in the early stage and the pozzolanic reaction in the late stage. The pores of cement-fly ash are found to be filled with the hydration products, despite the presence of a mass of pores in the interior.
\end{abstract}

\section{Introduction}

Thermal power is regarded as one of the most significant methods to generate electric energy. However, this process is frequently used to produce a large amount of fly ash in a solid waste, which makes a safe and effective treatment $[1-3]$. Part of the fly ash is utilized as an additive in other production activities to improve the performance of concrete. Otherwise, the fly ash could end up in landfills $[4,5]$. Fly ash stratum is characterized by low bearing capacity, higher settlement, and long settlement period due to the presence of fly ash $[6,7]$. These properties could pose a severe threat to the safety of buildings. The cementfly ash shows advantages such as high efficiency, convenience, and low cost, for which it has been widely used in the weak stratum where high water content and high compressibility are a commonplace [8-10].

To date, plenty of studies have been performed to investigate the mechanical properties of fly ash concrete by exploring the characteristics of adding fly ash into concrete. Meanwhile, the static characteristics of fly ash concrete have been analyzed in detail. The relevant results have clearly indicated the changes to the mechanical properties such as unconfined compressive strength and microstructure. Golewski [11] compared $20 \%$ and $30 \%$ fly ash content on the performance of concrete, which led to the discovery that the strength of the test specimens increased with the fly ash content. Meanwhile, the fracture toughness was enhanced. As indicated by Xiao et al. [12], the initial increase in strength of cement soil mixed with fly ash was lower 
compared to pure cement soil. After 28 days, the strength of fly ash cement-soil increased at a faster pace due to pozzolanic reaction. Fan et al. [13] conducted analysis of the effect created by mortar with different replacement ratios of fly ash-to-low-heat Portland cement, which led to the conclusion that fly ash could be effective in reducing the total heat and heat rate of hydration of Portland cement, despite the hydrate phase species remaining unchanged throughout the process. Deschner et al. [14] carried out a study on the hydration reaction of low-calcium fly ash and calcium silicate cement from the microscopic point with the assistance of X-ray diffraction (XRD), obtaining the result that fly ash played role of fillers in the early hydration reaction system and the content of $\mathrm{Ca}(\mathrm{OH})_{2}$ reduced at a slow pace in the solution, indicating that the pozzolanic reaction increased the late strength. As the aforementioned studies on the mechanical properties of test are primarily focused on the fly concrete, they could only provide the basic theories on the cement-fly ash system.

However, the focus of these studies is mainly placed on the experimental results obtained under static load. By contrast, the research focusing on the characteristics of impact load remains quite limited. With regard to engineering projects, the cement-fly ash foundation is subject to both static load and dynamic load, for instance, construction vibrations, vehicle-induced vibrations, earthquake, and other types of dynamic load [15-18]. As for dynamic load, it tends to have a significant impact on the performance of materials and structures, for which it is of great significance to conduct a study on the mechanical properties possessed by cement-fly ash under dynamic load.

At present, the split Hopkinson pressure bar (SHPB) device has been extensively applied to assess the dynamic mechanical properties exhibited by the materials with a strain rate of $10^{2} \mathrm{~s}^{-1}-10^{4} \mathrm{~s}^{-1}[19,20]$. Chen et al. [21] adopted the method of SHPB to carry out a study on the dynamic mechanical properties of cement composites with different fly ash contents, which led to the discovery that the fly ash cement composites showed strain rate dependency and maintained plastic flow during the impact process. Mohamed et al. [22] conducted a SHPB test and applied other methods to investigate the mechanical properties of concrete under high-volume fly ash with a strain rate ranging from 30.12 to $101.42 \mathrm{~s}^{-1}$, which led to the results indicating that the impact resistance of fly ash cement specimens was more desirable compared to pure cement. Chien et al. [23] assessed the influence of two different methods (static compression and SHPB experiments) on the cement-fly ash samples, which led to the conclusion that the strain rate had a more significant impact on the strength.

Up to now, a number of studies have been conducted on the work of fly ash as an ameliorant to enhance the properties of concrete. However, the number of investigations about fly ash stabilized by cement remains limited. Therefore, in this work, the unconfined compressive strength test and the impact test were adopted to study the mechanical properties of cement-fly ash. Meanwhile, the variations in microstructure and material were obtained using XRD and SEM.

\section{Materials and Methods}

2.1. Experimental Materials. The fly ash used in the experiment was collected from a construction site located in Shangyao, Huainan city, China. The field was covered with fly ash that is the by-product of a power plant, and fly ash was widely distributed across the plant. To remove soil, the surface clay layer was removed in the first place, with the depth of soil being 2-3 meters. The undisturbed soil was mostly powdery of gray-brown color, containing agglomerates. The particle size composition of the fly ash is shown in Table 1, and the chemical composition index is presented in Table 2. According to the table, the fly ash refers to lowgrade and low-calcium raw fly ash.

The Portland composite cement of the strength level of 32.5 was adopted.

2.2. Test Principle. In accordance with the standard of Technical code for ground treatment of buildings (JGJ792012), the fly ash was first filtered using a $5 \mathrm{~mm}$ sieve to remove impurities such as agglomeration and organics, before being placed at $105^{\circ} \mathrm{C}$ to obtain the dry fly ash.

2.3. Preparation Samples of UCS Test. In engineering, the value of cement content was $12 \%$ in cement-fly ash, for which the content of cement was set to $12 \%$ (mass ratio to dry fly ash) during the production of samples. The relevant parameters of the unconfined compression test are listed in Table 3 . The dried fly ash, water, and cement with the mix proportion were thoroughly mixed in the blender to ensure uniformity. The $100 \mathrm{~mm}$ cube samples were used (with the release agent applied evenly in the mold). The molds with mixture were placed into the concrete standard curing room until the removal of the molds. Subsequently, the cement-fly ash samples were placed in a $\mathrm{Ca}(\mathrm{OH})_{2}$ solution for curing until the curing time was reached.

2.4. Preparation Samples of SHPB Test. In order to prevent the potential size effect on the split Hopkinson pressure bar (SHPB) test $[24,25]$, the mixtures of fly ash cement and water were poured into a cylindrical mold with a height of $25 \mathrm{~mm}$ and a diameter of $50 \mathrm{~mm}$ for the impact test to be conducted. Table 4 shows the relevant parameters of the impact test. Both sample production and curing were performed to the same standard as the unconfined compressive test.

\subsection{Experimental Apparatus}

2.5.1. The Test Machine of UCS. The UCS tests were performed on a WAW-1000 universal test machine at the State Key Laboratory of Mining Response and Disaster Prevention and Control in Deep Coal Mine, Anhui University of Science and Technology. As seen from Figure 1(a), the unconfined compression test apparatus was used to perform the test, and Figure 1(b) illustrates the test sample used for unconfined compressive test. 
TABle 1: Particle size composition of the fly ash.

\begin{tabular}{lc}
\hline Particle size group $(\mathrm{mm})$ & Average $(\%)$ \\
\hline $5-2.0$ & 2.17 \\
$2.0-1.0$ & 1.06 \\
$1.0-0.5$ & 2.13 \\
$0.5-0.25$ & 8.12 \\
$0.25-0.1$ & 77.90 \\
$0.1>$ & 8.63 \\
\hline
\end{tabular}

TABLe 2: Chemical composition of fly ash.

\begin{tabular}{lc}
\hline Chemical composition & Average (\%) \\
\hline $\mathrm{SiO}_{2}$ & 58.49 \\
$\mathrm{Al}_{2} \mathrm{O}_{3}$ & 29.19 \\
$\mathrm{Fe}_{2} \mathrm{O}_{3}$ & 4.65 \\
$\mathrm{CaO}$ & 2.33 \\
$\mathrm{~K}_{2} \mathrm{O}$ & 1.32 \\
$\mathrm{SO}_{3}$ & 1.30 \\
Loss on ignition & 0.5 \\
\hline
\end{tabular}

TABLE 3: The parameters of unconfined compressive test.

\begin{tabular}{lccc}
\hline $\begin{array}{l}\text { Cement } \\
\text { content }(\%)\end{array}$ & $\begin{array}{c}\text { Curing time } \\
(\mathrm{d})\end{array}$ & $\begin{array}{c}\text { Moisture } \\
\text { content }(\%)\end{array}$ & $\begin{array}{c}\text { Samples of each } \\
\text { group }\end{array}$ \\
\hline 12 & $\begin{array}{c}7,30,60,90, \\
\text { and } 120\end{array}$ & 35.00 & 6 \\
\hline
\end{tabular}

TABLE 4: The parameters of dynamic impact test.

\begin{tabular}{lccc}
\hline $\begin{array}{l}\text { Cement } \\
\text { content }(\%)\end{array}$ & $\begin{array}{c}\text { Curing time } \\
(\mathrm{d})\end{array}$ & $\begin{array}{c}\text { Moisture } \\
\text { content }(\%)\end{array}$ & $\begin{array}{c}\text { Samples of each } \\
\text { group }\end{array}$ \\
\hline 12 & $\begin{array}{c}7,30,60, \\
\text { and 90 }\end{array}$ & 35.00 & 4 \\
\hline
\end{tabular}

2.5.2. The SHPB Test Device. As shown in Figure 2, a small amount of Vaseline was applied to the rounded surfaces for reducing friction [26]. The SHPB test device was employed to assist with this study, obtained from the School of Civil Engineering and Architecture of Anhui University of Science and Technology. The length of the striker bar, incident bar, and transmitted bar is $0.60 \mathrm{~m}, 2.40 \mathrm{~m}$, and $1.20 \mathrm{~m}$, respectively. The density, elastic modulus, and longitudinal wave velocity of each bar are $7.8 \mathrm{~g} / \mathrm{cm}^{3}, 210 \mathrm{GPa}$, and $5190 \mathrm{~m} / \mathrm{s}$. The value of gas pressure is set to $0.2 \mathrm{MPa}$ in this study.

2.5.3. XRD and SEM Test. In order to establish the reaction mechanism of materials in cement-fly ash, the XRD and SEM devices sourced from the Analytical Testing Center of Anhui University of Science and Technology were applied in the study. The XRD patterns of pure fly ash and the cementfly ash sample with different curing time were analyzed by using MDI Jade software.

\section{Test Results and Analysis}

When the cement-fly ash samples were subject to vibration, black bubbles were observed on the surface of the cement-fly ash samples. In the meantime, a large number of colorless bubbles emerged from the periphery of mold, and plenty of free water was precipitated on the surface. After the curing time had been reached $(7 \mathrm{~d}, 30 \mathrm{~d}, 60 \mathrm{~d}, 90 \mathrm{~d}, 120 \mathrm{~d})$, the integrity of the test block reached a satisfactory level. The samples with flat surface and no obvious holes were selected for the UCS and DCS tests.

\subsection{Analysis of Unconfined Compressive Test Results}

3.1.1. The Relationship Curves of Stress-Strain under Static Load. The method of unconfined compressive test is adopted according to Technical code for ground treatment of buildings (JGJ79-2012). The six samples were collected from each group for the unconfined compressive test, with the loading rate set to $3 \mathrm{~mm} / \mathrm{min}$. After removal of the error data, the average value was taken as the strength value of the test samples. As shown in Figure 3, it can be seen that the failure patterns of UCS test samples vary under different curing times. When the curing time is $30 \mathrm{~d}$, two main cracks were presented; in the meantime, transverse expansion cracks were obtained in the upper parts of sample. However, when the curing time is upregulated to $120 \mathrm{~d}$, a small part of fragments peeled from the sample and an approximately linear crack was run through the whole sample. It is suggested that with an increase of curing time, the failures begin to be changed from the plastic to the brittle deformation.

The stress-strain curves of $7 \mathrm{~d}, 30 \mathrm{~d}, 60 \mathrm{~d}, 90 \mathrm{~d}$, and $120 \mathrm{~d}$ of cement-fly ash samples with the cement content of $12 \%$ are shown in Figure 4. When the curing time ranges from 0 to $30 \mathrm{~d}$, the test samples pass through the initial compaction section, and then the elastic phase and the yielding stage are presented, respectively. When the curing time is extended from $30 \mathrm{~d}$ to $120 \mathrm{~d}$, a little elastic phase and a platform segment are observed between the initial compaction section and the elastic phase, which suggests that the cement-fly ash samples show a clear sign of plastic failure in the initial stage of curing time $(7 \mathrm{~d})$, and the brittle failure is manifested in the later curing time. Therefore, the typical relationship of stress-strain is determined by analyzing the relationship between stress-strain and varying curing time, with the results presented in Figure 5.

Figure 5 illustrates the typical stress-strain characteristic curve of cement-fly ash, which can be roughly split into 6 different sections. The first one is the initial compaction stage $(\mathrm{o}-\mathrm{a})$, when the particles are vertically displaced by force and the pore volume is reduced. The second one is the initial elastic stage (a-b), when the curve is approximately straight. The cement-fly ash samples exhibit approximate elastic deformation, which is caused by the hydration products and the inclusions of hydrated product. Besides, the particles of fly ash are compacted under the condition of load, and the pore volume is further reduced. The third one is the platform stage (b-c). This section lasts from the compaction section to the elastic stage. The hydration products, the inclusion of fly ash and hydrated products, and the unreacted materials contribute to the formation of a stress structure as facilitated by the effect of compaction. Moreover, the internal pores of the test sample are gradually reduced to their minimum. The fourth one is the 


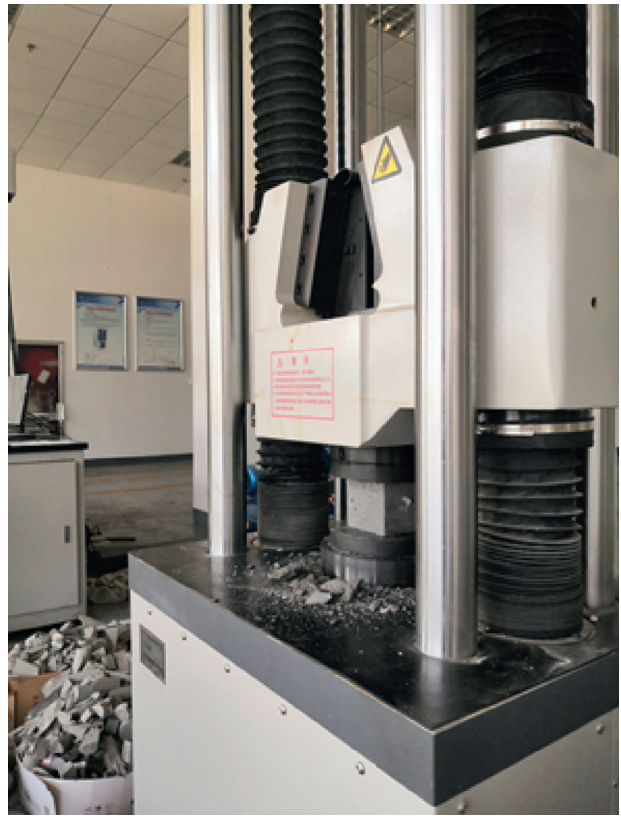

(a)

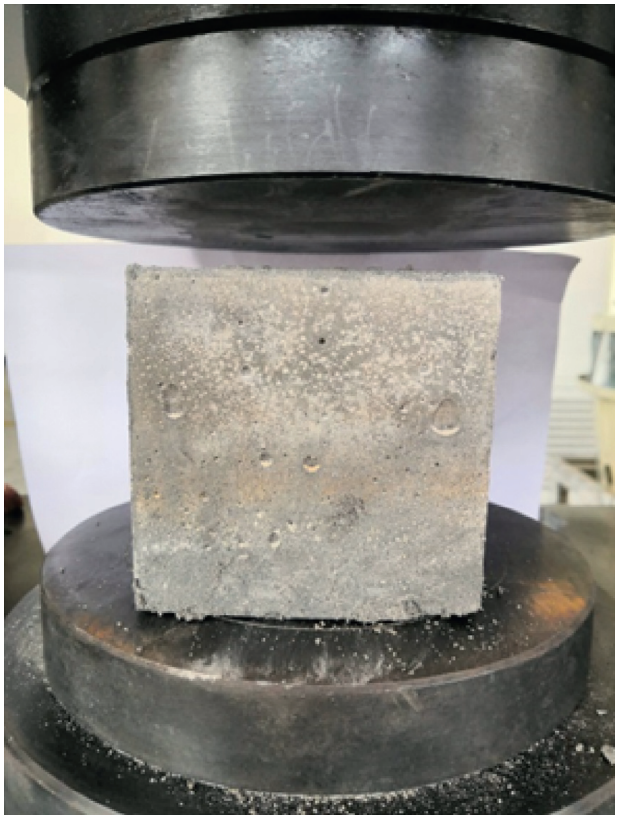

(b)

Figure 1: The unconfined compressive strength test.

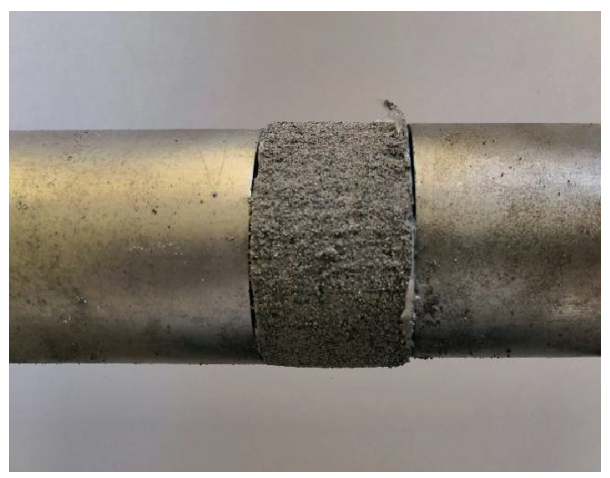

FIgure 2: The SHPB test.

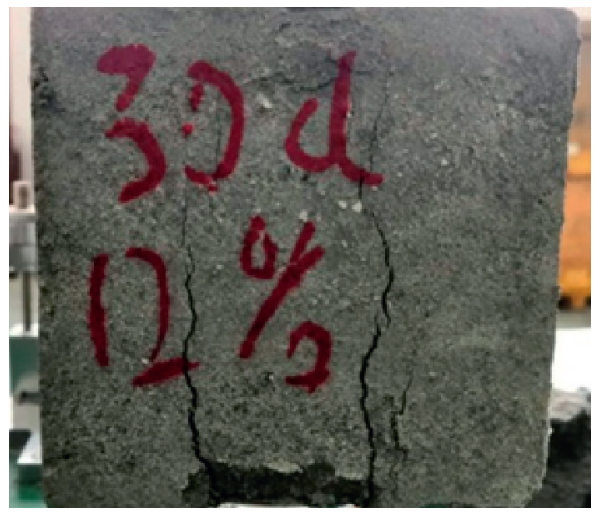

(a)

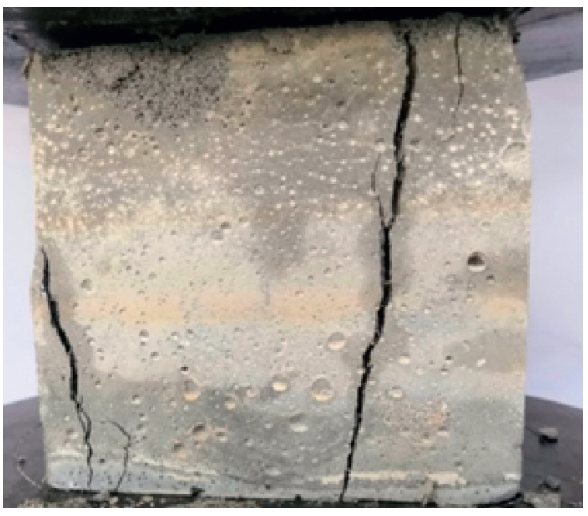

(b)

Figure 3: The failure patterns of UCS test samples. 


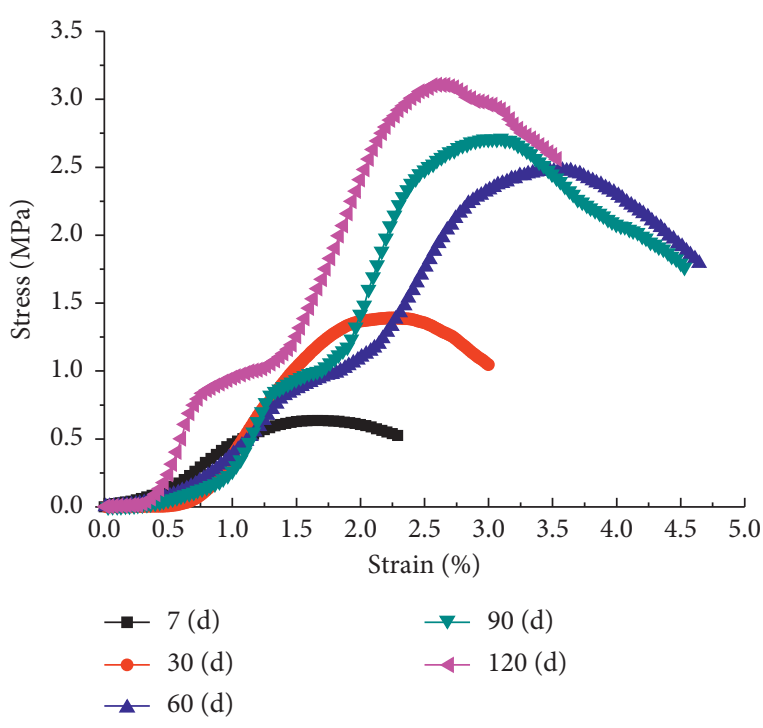

FIgURE 4: The static stress-strain curves of cement-fly ash samples.

elastic phase (c-d), when the stress is on the rise with strain and the curve conforms approximately to elastic deformation. The fifth one is the yield stage (d-e). As $\varepsilon$ increases, the growth rate of stress is reduced to zero gradually. Meanwhile, the value of stress is maximum. The sixth and last one is the failure stage (ef); as the strain continues to increase, the stress gradually declines and the test sample breaks.

3.1.2. The Variation Laws of UCS. As shown in Figure 6, when the curing time is extended from $7 \mathrm{~d}$ to $120 \mathrm{~d}$, the UCS increases gradually from $0.64 \mathrm{MPa}$ to $3.14 \mathrm{MPa}$. The UCS of cement-fly ash samples ( $7 \mathrm{~d}$ ) is shown to be $0.64 \mathrm{MPa}$, and the UCS at the curing time of $30 \mathrm{~d}$ is observed to surge by $115.62 \%$, to $1.38 \mathrm{MPa}$. At the curing time of $60 \mathrm{~d}$, the UCS is seen on the rise from $1.38 \mathrm{MPa}(30 \mathrm{~d})$ to $2.32 \mathrm{MPa}(60 \mathrm{~d})$, with the rate of increase reaching $68.12 \%$. Nevertheless, when the curing time reaches $90 \mathrm{~d}$, the rate of increase for UCS plunges from $68.32 \%$ $(60 \mathrm{~d})$ to merely $18.53 \%$ (90 d), while the value of UCS reaches 2.75 MPa. When the curing time is extended to $120 \mathrm{~d}$, the growth rate decreases on a continued basis to $14.18 \%$, with UCS reaching $3.14 \mathrm{MPa}$, which suggests that the value of UCS increases with curing time and the growth rate decreases, from $115.62 \%$ to the minimum value of $14.18 \%$. The variation law of growth rate is that the value of early curing time $(0-60 \mathrm{~d})$ is higher than that in the later stage.

3.2. Analysis of SHPB Test Results. As shown in Figure 7, the typical waveforms of the cement-fly ash samples are discovered, including incident pulse, transmitted pulse, and reflected pulse, and the waveforms are smooth (select the $30 \mathrm{~d}$ sample waveforms).

As can be observed from Figure 8, under the condition of curing time, the cement-fly ash samples display different patterns of failure depending on fragment size and the number of fragments. At the gas pressure of $0.20 \mathrm{MPa}$, the failure modes of cement-fly ash are basically powdery with varying curing time. However, with the increase in curing

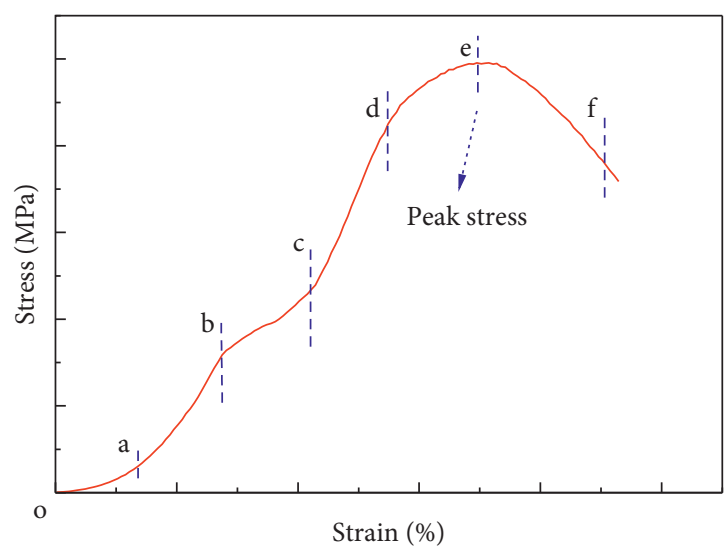

FIgURE 5: Typical stress-strain characteristic curve of cement-fly ash.

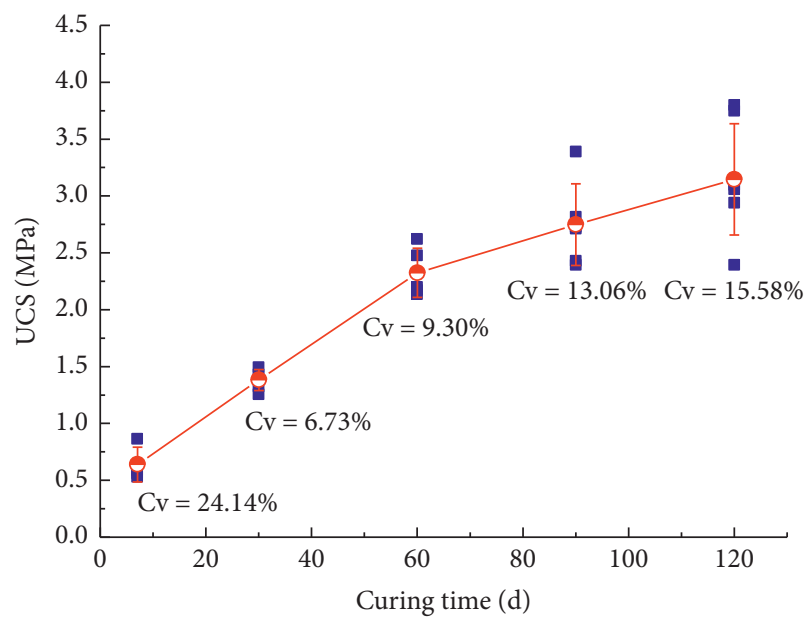

FIGURE 6: Variation law of UCS.

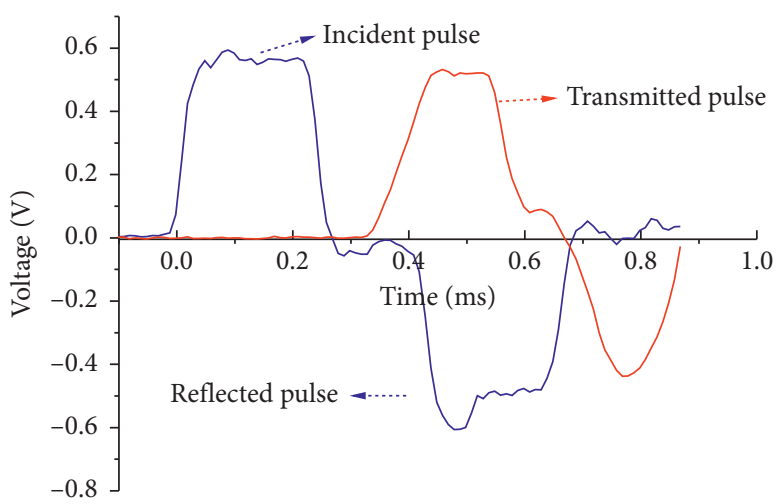

FIGURE 7: The typical waveforms of the samples.

time, the degree of broken fragments and amount of powdered materials decrease obviously. In the meantime, the size of fragments and the number of broken fragments increase remarkably, indicating that the degree of sample integrity increases with the curing time.

According to the two-wave method, the stress and strain of the samples can be obtained, respectively [27]. The 

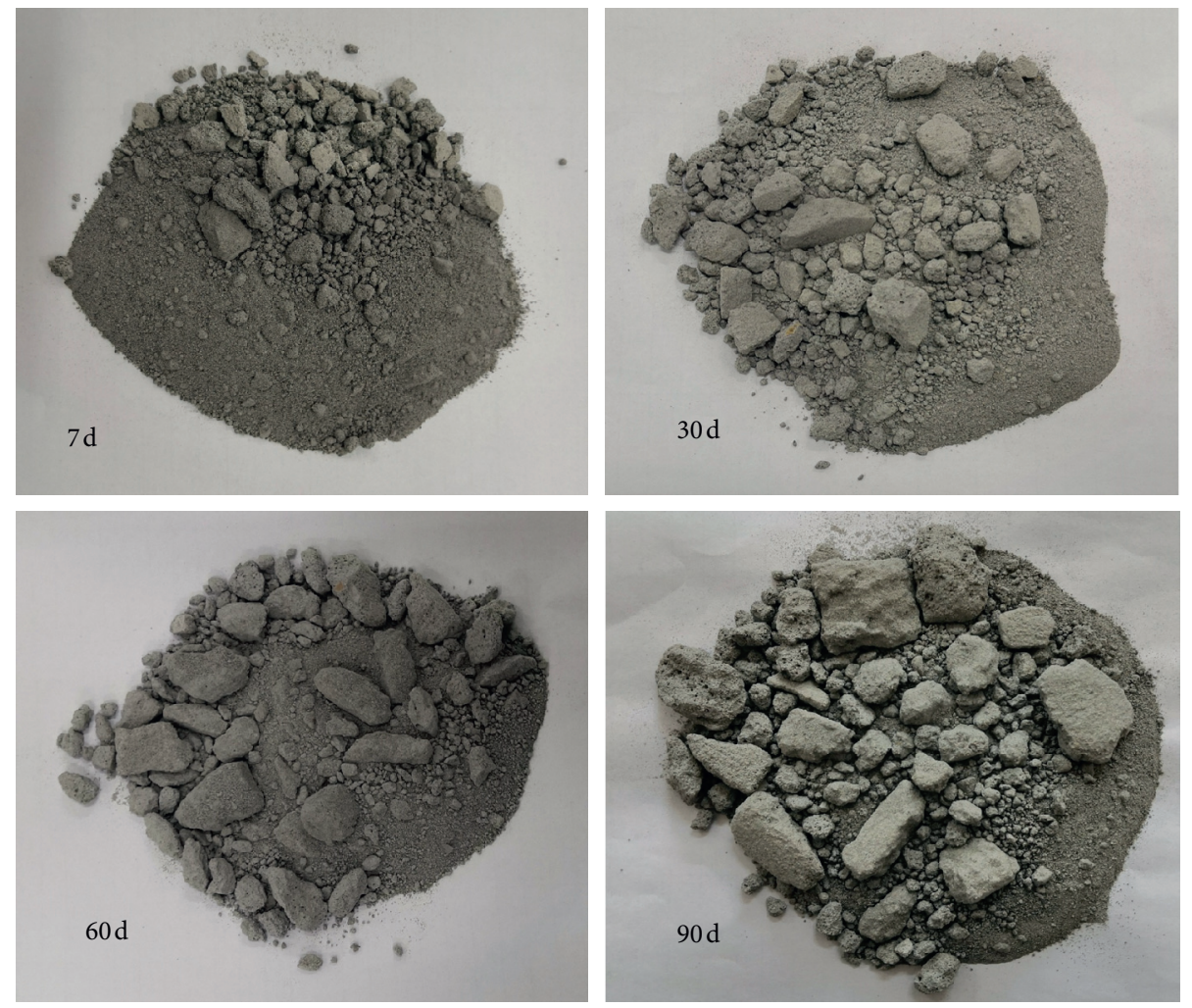

Figure 8: The failure patterns of SHPB test samples.

relevant analytical formula applied to the determination of parameters is expressed as follows:

$$
\begin{aligned}
& \varepsilon_{S}(t)=\frac{2 c_{0}}{L_{S}} \int_{0}^{t} \varepsilon_{r}(t) \mathrm{d} t, \\
& \sigma_{S}(t)=\frac{S_{B} E}{S_{S}} \varepsilon_{t}(t),
\end{aligned}
$$

where $\varepsilon_{S}(t)$ and $\sigma_{S}(t)$ represent the strain and stress, respectively, $c_{0}, S_{B}$, and $E$ denote the longitudinal wave velocity, cross-sectional area, and elastic modulus of the bar, respectively, $L_{S}$ and $S_{S}$ indicate, respectively, the length and the cross-sectional area of the cement-fly ash samples, and $\varepsilon_{r}(t)$ and $\varepsilon_{t}(t)$ represent the reflected pulse and the transmitted pulse, respectively.

It can be observed from Figure 9(a) that under different curing times $(7,30,60$, and $90 \mathrm{~d})$, the stress-strain curves of cement-fly ash show different characteristics of failure. For instance, when the curing time increases from 7 to $60 \mathrm{~d}$, the curves exhibit approximate elastic deformation firstly and then enter platform stage. After the stress peak value, it decreases rapidly, indicating a plastic failure. However, when curing for $90 \mathrm{~d}$, the typical failure of brittle is shown in the stress-strain curve and the stress increases with growth of the strain until reaching the peak value. Finally, it decreases gradually. Additionally, as seen from Figure 9(b), as the curing time varies, DCS changes from the initial 1.04 MPa to $5.13 \mathrm{MPa}$. It is 1.04 , $1.99,3.85$, and $5.13 \mathrm{MPa}$, respectively, suggesting that the hydration products were generated constantly and the mechanical performance of cement-fly ash was enhanced.
There is a lot of information obtained from Figure 10(a), and the cement-fly ash shows variations of compression strength under static and impact load conditions. At the same curing time, the value of DCS is higher than that of UCS. DIF is defined as the modulus of DCS to UCS, and the formula of DIF is expressed as follows:

$$
\mathrm{DIF}=\frac{\sigma_{d}}{\sigma_{S}},
$$

where $\sigma_{d}$ and $\sigma_{S}$ represent the stress of SHPB and unconfined compression tests, respectively. In Figure 10(b), the change of the DIF and curing time is observed. When the curing time increases, the DIF decreases first, and then climbs back. Under the $7 \mathrm{~d}$ initial curing, the value of DIF is 1.64 but the DIF falls to the lowest value at 1.43 after a curing time of $30 \mathrm{~d}$. In comparison, the value of DIF increases with curing time, and the values of DIF with curing time of $60 \mathrm{~d}$ and $90 \mathrm{~d}$ being 1.66 and 1.87 , respectively. The experimental data indicate that the loadbearing capacity of cement-fly ash shows different characteristics under the static and impact load conditions, which means that the test samples are subjected to the impact test. The samples absorb more energy than that of static test, indicating that more cracks are produced in the samples and the compression strength increases.

\subsection{Analysis of Microstructure}

3.3.1. Analysis of XRD Phase. The XRD results of fly ash are shown in Figure 11. The phases of fly ash are mullite phase and quartz phase, respectively, as analyzed using the Jade 


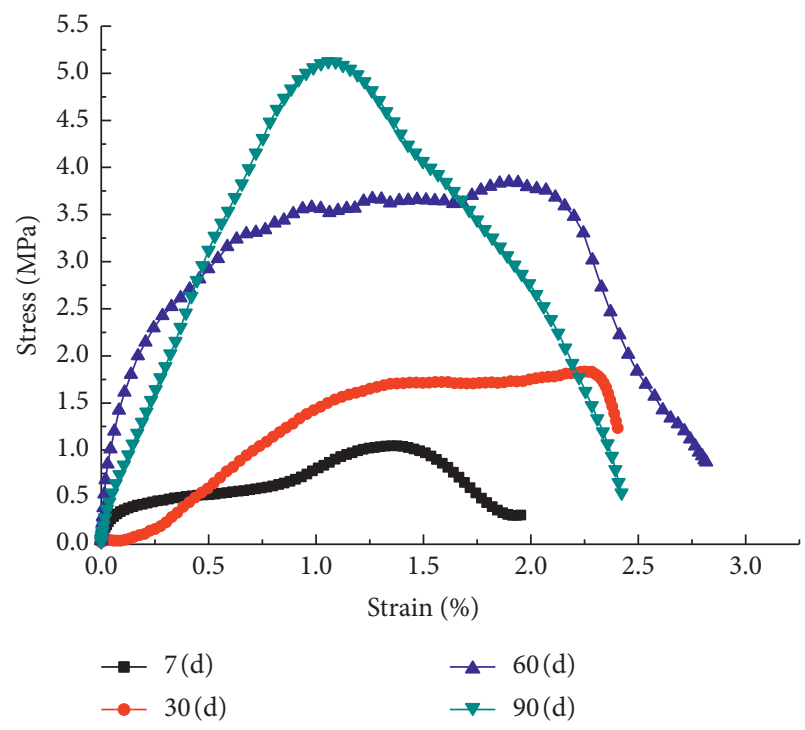

(a)

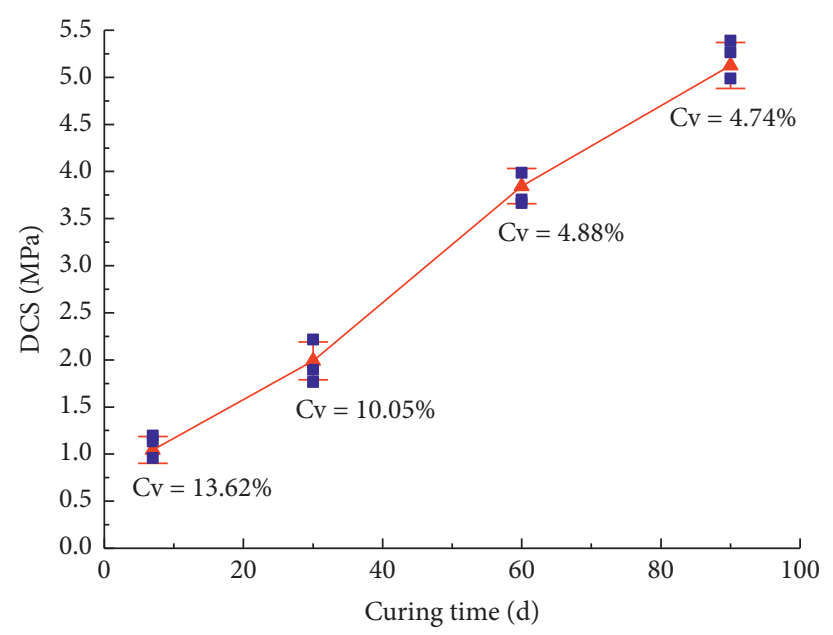

(b)

FIgURE 9: Test results of impact test. (a) The stress-strain curves of impact test. (b) Variation law of DCS.

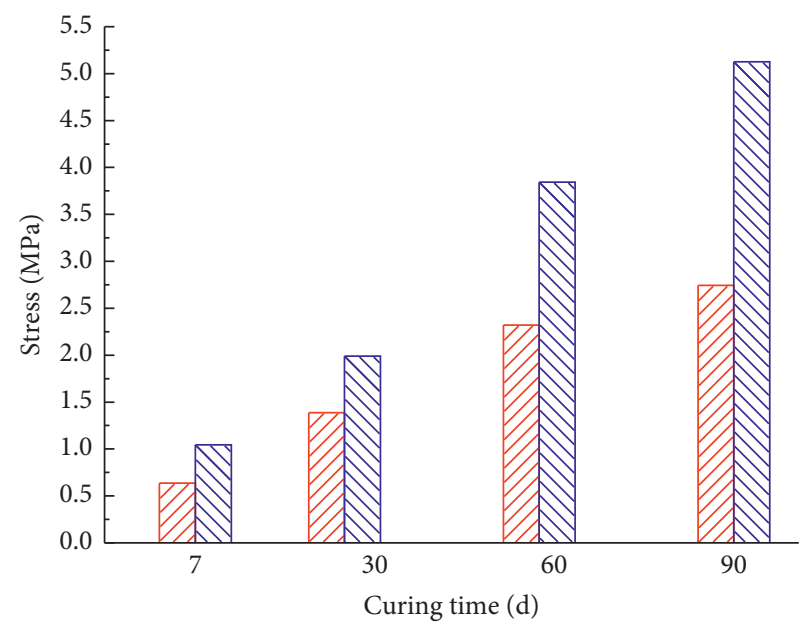

WIA - UCS
ZIIA - DCS

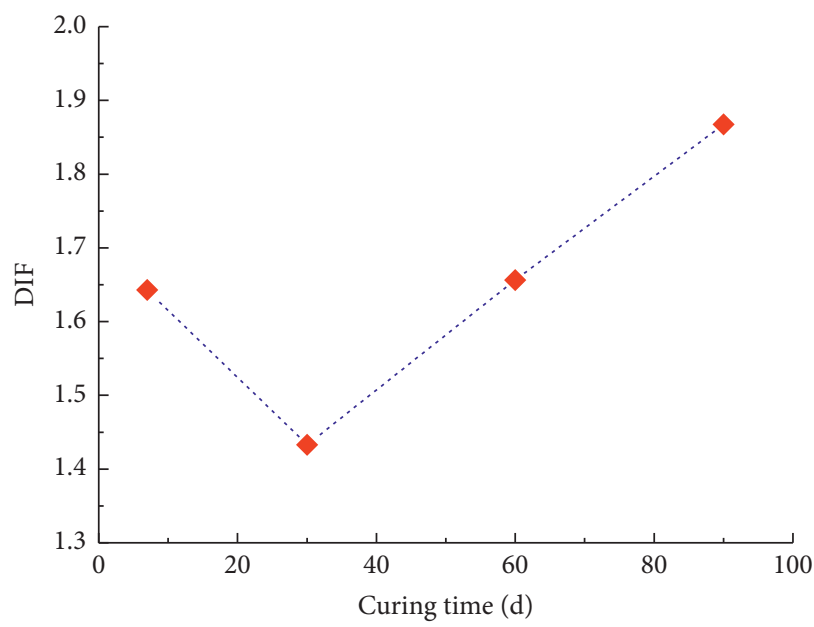

(b)

FIGURE 10: Relationship of strength between static and impact load test. (a) The relationship of DCS and UCS. (b) The curve of DIF with different curing times.

software. Despite this, even a small amount of $\mathrm{Fe}_{2} \mathrm{O}_{3}$ and $\mathrm{CaO}$ is not observed in the XRD spectrum.

To facilitate the study on the variation laws of material, two samples under the curing time of $7 \mathrm{~d}$ (number A) and $120 \mathrm{~d}$ (number B) were applied to conduct the test of XRD in cementfly ash composition. Figure 12 presents the XRD spectrum of A and $\mathrm{B}$ and fly ash, with the curve A suggesting that the gypsum has been generated. That is to say, the hydration of cement is maintained. In the meantime, the $\mathrm{CaCO}_{3}$ phase has been spotted in the spectrum. Nevertheless, in comparison with the fly ash, the diffraction peak value of quartz shows a sharp decline, which implies the start to the pozzolanic reaction. In curve $B$, the gypsum phase disappears, which can explain why the cement has hydrated completely while the diffraction peak of quartz continues a declining trend, indicating that the pozzolanic reaction of fly ash is the major source of hydration products in the later stage.

3.3.2. Analysis Results of SEM. The cement-fly ash samples of A $(7 \mathrm{~d})$ and B (120 d) were tested for the SEM, and the results are indicated in Figure 13.

As shown in Figure 13, the amount of hydration products increases with the curing time, suggesting that the 


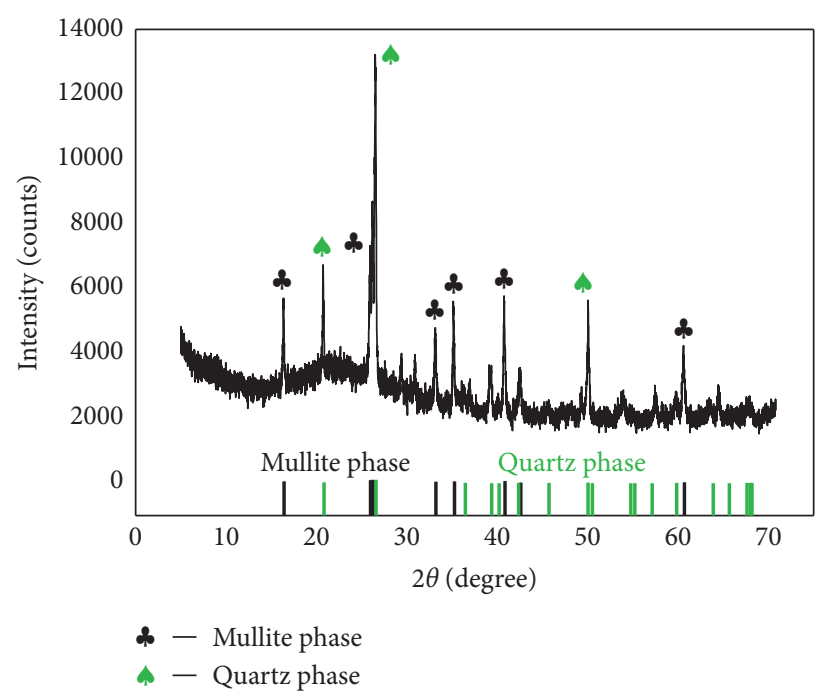

Figure 11: The XRD spectrum of fly ash.

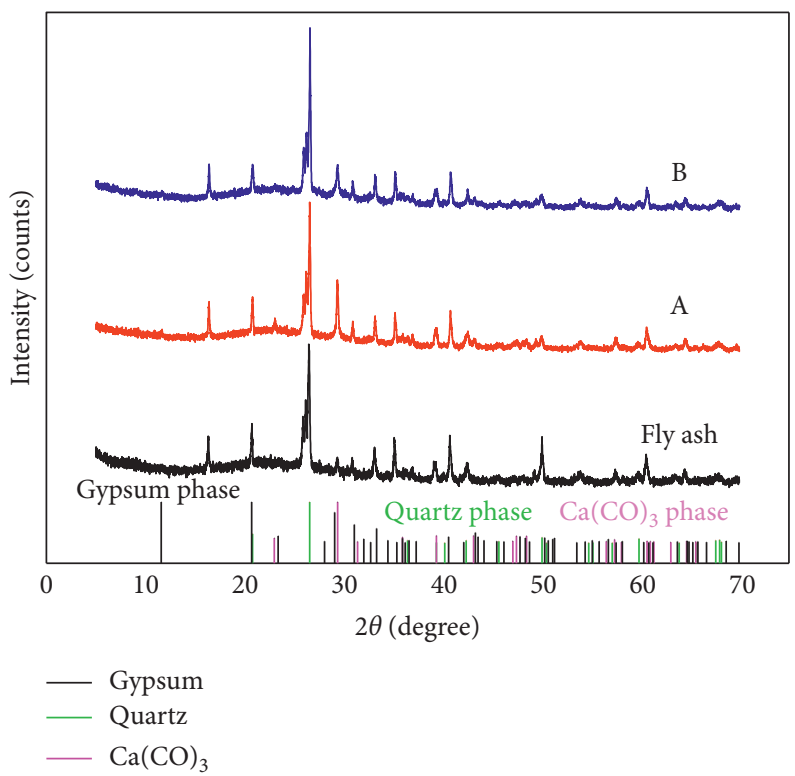

FIgURE 12: The XRD spectrums of test samples.

interspace in the cement-fly ash is reduced gradually and that the structure of cement-fly ash is made dense due to the effect of cementation. Under the curing time of $7 \mathrm{~d}$, the C-S$\mathrm{H}$ gel gives rise to inclusions by encapsulating microbeads and amorphous particles, which are filled in the pores of the cement-fly ash, despite a large number of pores present in the interspace between the inclusions of each other. The meshy C-S-H gel can be observed after the curing time is extended from $7 \mathrm{~d}$ to $120 \mathrm{~d}$. Under alkaline environment, the pozzolanic activity of fly ash is initiated, the products of the fly ash hydrating are attracted to the surface of fly ash particles, and the interspace continues to diminish.

From the XRD spectrums and the SEM image, it can be known that the cementation of cement-fly ash has two sources, with one being the cement hydration in the early stage and the other one being pozzolanic reaction in the later stage. The hydration of ordinary Portland cement is primarily $3 \mathrm{CaO} \cdot \mathrm{SiO}_{2}$ of the cement clinker minerals reacting with $\mathrm{H}_{2} \mathrm{O}$, and the reaction equation is expressed as follows:

$3 \mathrm{CaO} \cdot \mathrm{SiO}_{2}+n \mathrm{H}_{2} \mathrm{O}=x \mathrm{CaO} \cdot \mathrm{SiO}_{2} \cdot y \mathrm{H}_{2} \mathrm{O}+(3-x) \mathrm{Ca}(\mathrm{OH})_{2}$

The reaction equation is simplified as follows:

$$
\mathrm{C}_{3} \mathrm{~S}+n \mathrm{H}=\mathrm{C}-\mathrm{S}-\mathrm{H}+(3-x) \mathrm{CH}
$$

$\mathrm{C}_{3} \mathrm{~S}$ is a gel and has a structure of foil and fiber grain with a low crystallization degree. Besides, this structure shows a higher bearing capacity. A part of $\mathrm{CH}$ is precipitated as a sixplate crystal, and the rest dissolves into solution to facilitate the pozzolanic reaction. 


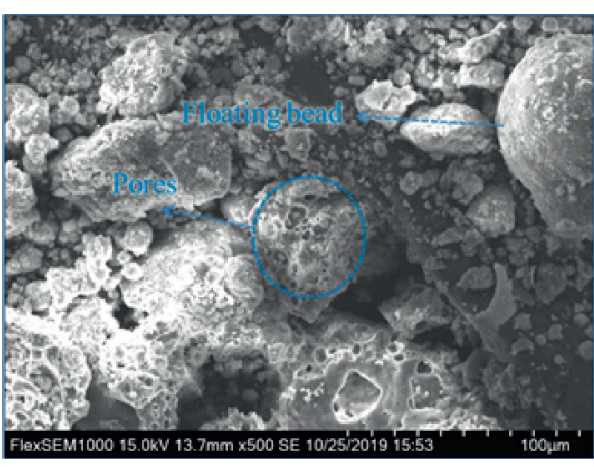

(a)

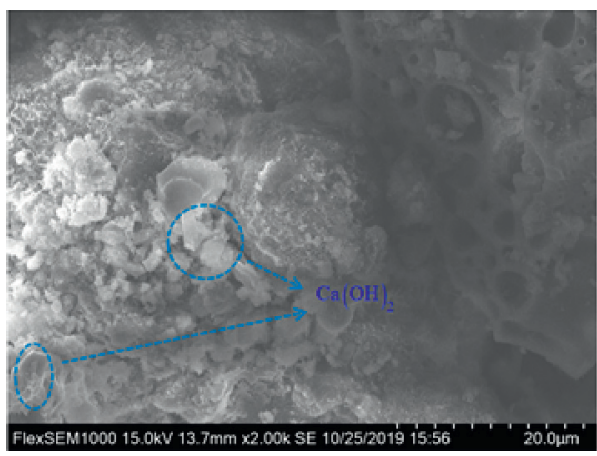

(c)

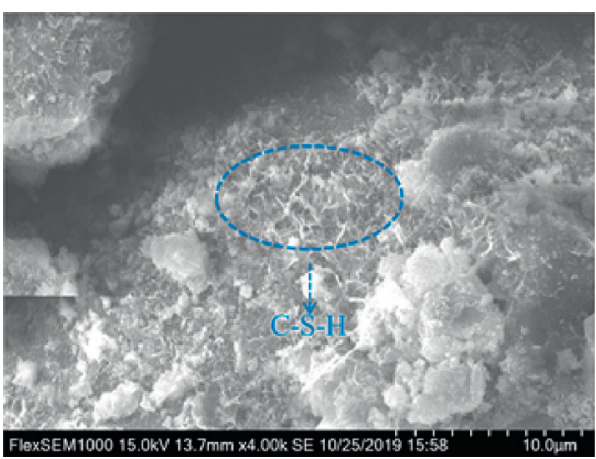

(e)

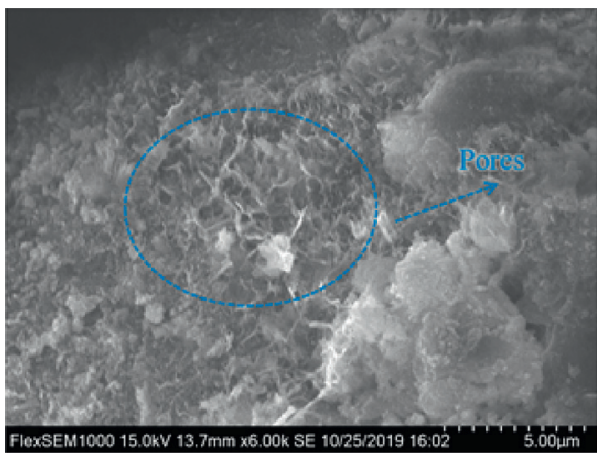

(g)

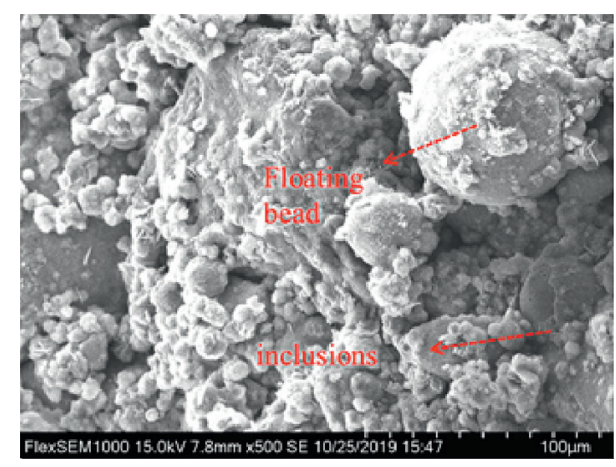

(b)

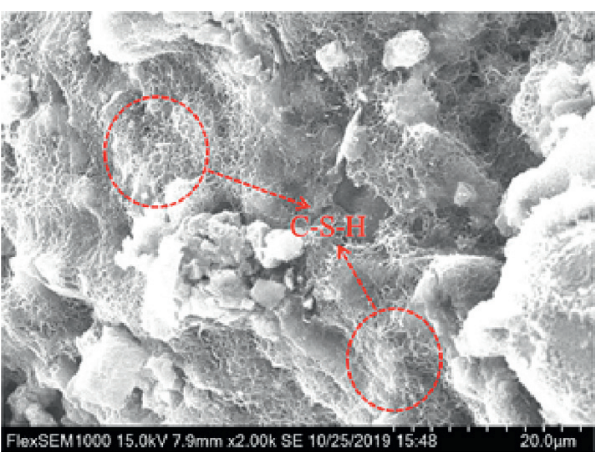

(d)

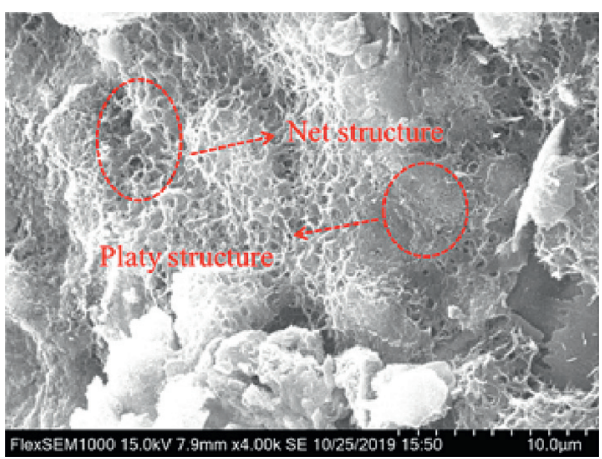

(f)

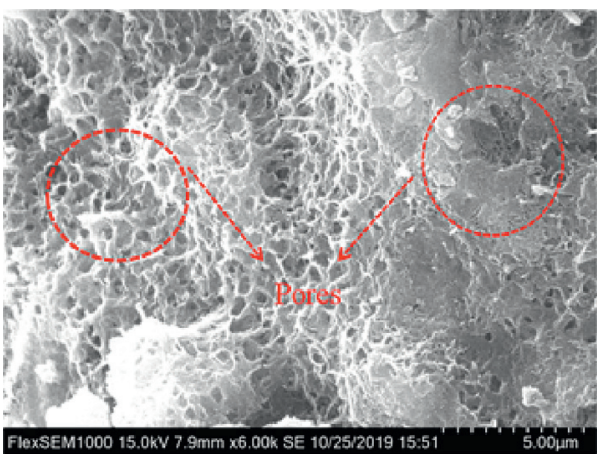

(h)

Figure 13: SEM observations of A and B. (a) A1 (×500). (b) B1 (×500). (c) A2 (×2000). (d) B2 (×2000). (e) A3 (×4000). (f) B3 (×4000). (g) A4 (×6000). (h) B4 (×6000). 
In alkaline environment, the glass phase on the gray surface dissolves at a slow pace, and the active objects of $\mathrm{SiO}_{2}, \mathrm{Al}_{2} \mathrm{O}_{3}$ can be obtained. These substances are capable of reaction with water and $\mathrm{CH}$ to generate $x \mathrm{CaO} \cdot \mathrm{SiO}_{2} \cdot n \mathrm{H}_{2} \mathrm{O}$ and $x \mathrm{CaO} \cdot \mathrm{Al}_{2} \mathrm{O}_{3} \cdot n \mathrm{H}_{2} \mathrm{O}$, and the reaction equations are shown as follows:

$$
\mathrm{SiO}_{2}+x \mathrm{Ca}(\mathrm{OH})_{2}+(n-1) \mathrm{H}_{2} \mathrm{O}=x \mathrm{CaO} \cdot \mathrm{SiO}_{2} \cdot n \mathrm{H}_{2} \mathrm{O}
$$

$$
\mathrm{Al}_{2} \mathrm{O}_{3}+x \mathrm{Ca}(\mathrm{OH})_{2}+(n-1) \mathrm{H}_{2} \mathrm{O}=x \mathrm{CaO} \cdot \mathrm{Al}_{2} \mathrm{O}_{3} \cdot n \mathrm{H}_{2} \mathrm{O}
$$

\section{Conclusions}

In this study, the static mechanical properties of cement-fly ash with varying curing time were determined in the first place for comparison between static and dynamic load. Then, $7 \mathrm{~d}$ curing and $120 \mathrm{~d}$ curing were applied to the XRD and SEM. Finally, the mechanism of cement-fly ash was explained in detail. The conclusions drawn from the study are as follows:

(1) The UCS experiences an increase as the curing time is extended, and the growth rate of UCS in the initial stage of the curing time is higher than that in the later stage. After the curing time of $30 \mathrm{~d}$, the stress-strain curves of static load can be split into six different sections including initial compaction stage, initial elastic stage, platform stage, elastic phase, yield stage, and failure stage.

(2) Under the curing time varying from 0 to $90 \mathrm{~d}$, the curves of the cement-fly ash samples exhibit the characteristics of plastic failure in the impact test. However, brittle failure was clearly observed obviously at the curing time of $90 \mathrm{~d}$. The DIF value decreases first and then increases gradually, with the lowest value of 1.43 obtained on $30 \mathrm{~d}$.

(3) As revealed by the microstructure and mineral composition analysis, a mass of pores was present in cement-fly ash, and the hydration of cement is the main source of hydrated products in the initial stage. However, the hydrated products are derived from the pozzolanic reaction of the fly ash in the later stage.

The mechanical properties of cement-fly ash have been achieved under static and impact load. However, in the engineering project, various curing agents will be added in the cement-fly ash so that the characteristics of the cement-fly ash with different curing agents will be revealed in the future research.

\section{Data Availability}

The data used to support the findings of this study are available from the corresponding author upon request.

\section{Conflicts of Interest}

The authors declare that there are no conflicts of interest regarding the publication of this paper.

\section{Acknowledgments}

This research was funded by the Major Universities Natural Science Research Project in Anhui Province (KJ2016SD19), the National Natural Science Foundation of China (41977236, 41672278, and 41271071), and the Natural Science Foundation of Jiangxi Province (2019ACBL20002). The authors sincerely thank the School of Civil Engineering and Architecture, National Engineering Laboratory for Deep Shaft Construction Technology in Coal Mine in Anhui University of Science and Technology, for providing the experiment conditions.

\section{References}

[1] Z. X. Yue and J. N. Chen, "Fly ash the status of resourceoriented utilization in construction material," Advanced Materials Research, vol. 753-755, pp. 628-631, 2013.

[2] S. d. Mao, Z. Li, and Y. Fang, "Current status of research on the utilization of fly ash," Concrete, vol. 7, pp. 82-84, 2011.

[3] Z. T. Yao, X. S. Ji, P. K. Sarker et al., "A comprehensive review on the applications of coal fly ash," Earth-science Reviews, vol. 141, pp. 105-121, 2015.

[4] M. Ahmaruzzaman, "A review on the utilization of fly ash," Progress in Energy and Combustion Science, vol. 36, no. 3, pp. 327-363, 2010.

[5] Y. S. Luo, J. Li, and A. Chan, "Study on the engineering property of mixed-soil fly ash," Advances in Environmental Geotechnics, vol. 10, pp. 721-727, 2009.

[6] H. K. Kim and H. K. Lee, "Coal bottom ash in field of civil engineering: a review of advanced applications and environmental considerations," KSCE Journal of Civil Engineering, vol. 19, no. 6, pp. 1802-1818, 2015.

[7] P. S. Toth, H. T. Chan, and C. B. Cragg, "Coal ash as structural fill, with special reference to Ontario experience," Canadian Geotechnical Journal, vol. 25, no. 4, pp. 694-704, 1988.

[8] J. P. Ming and W. B. Zhao, "Triaxial test and calculation about collapsibility deformation of coal ash," Rock and Soil Mechanics, vol. 25, pp. 32-38, 2004.

[9] Q. Meng, L. Shao, and Q. Y. Shi, "Experimental study on the mechanical properties of fly ash cement soil," Journal of University of Shanghai for Science and Technology, vol. 39, pp. 490-496, 2017.

[10] H. Yanli, "Backfilling technology of substituting waste and fly ash for coal underground in China coal mining area," Environmental Engineering \& Management Journal, vol. 10, no. 6, pp. 769-775, 2011.

[11] G. L. Golewski, "Effect of curing time on the fracture toughness of fly ash concrete composites," Composite Structures, vol. 185, pp. 105-112, 2018.

[12] H. Xiao, W. Shen, and F. H. Lee, "Engineering properties of marine clay admixed with Portland cement and blended cement with siliceous fly ash," Journal of Materials in Civil Engineering, vol. 29, no. 10, Article ID 04017177, 2017.

[13] Z. H. Fan, J. J. Zeng, J. B. Xiong et al., "Hydration characteristic of low heat Portland cement mixtures with fly ash or slag," Port \& Waterway Engineering, vol. 599, pp. 63-69, 2019.

[14] F. Deschner, F. Winnefeld, B. Lothenbach et al., "Hydration of Portland cement with high replacement by siliceous fly ash," Cement and Concrete Research, vol. 42, no. 10, pp. 1389-1400, 2012.

[15] S. Paya, A. N. Mohammad, U. J. Alengaram et al., "Engineering properties of lightweight aggregate concrete 
containing limestone powder and high volume fly ash," Journal of Cleaner Production, vol. 135, pp. 148-157, 2016.

[16] C. Gunasekara, D. Law, and S. Setunge, "Design of ternary blend high-volume fly ash concrete mixes using hydrated lime," in Proceedings of the 6th International Conference on Durability of Concrete Structures, vol. 18, Leeds, UK, 2018.

[17] Y. Al-Salloum, T. S. M. Almusallam, H. I. Abbas et al., "Rate dependent behavior and modeling of concrete based on SHPB experiments," Cement and Concrete Composites, vol. 55, pp. 34-44, 2015.

[18] Q. Sun, B. Li, S. Tian et al., "Creep properties of geopolymer cemented coal gangue-fly ash backfill under dynamic disturbance," Construction and Building Material, vol. 191, no. 10, pp. 644-654, 2018.

[19] J. E. Field, S. M. Walley, and W. G. Pround, "Review of experimental techniques for high rate deformation and shock studies," International Journal of Impact Engineering, vol. 30, no. 7, pp. 725-772, 2004.

[20] S. Q. Zhou, D. W. Zhou, Y. F. Zhang, W.-j. Wang, and D. Li, "Research on the dynamic mechanical properties and energy dissipation of expansive soil stabilized by fly ash and lime," Advances in Materials Science and Engineering, vol. 2019, Article ID 5809657, 13 pages, 2019.

[21] Z. T. Chen, Y. Z. Yang, and Y. Tao, "Impact properties of engineered cementitious composites with high volume fly ash using SHPB test," Journal of Wuhan University of TechnologyMaterials Science Edition, vol. 27, 2012.

[22] H. M. Mohamed, A. M. Azrul, H. Roszilah et al., "Dynamic properties of high volume fly ash nanosilica (NVFANS) concrete subjected to combined effect of high strain rate and temperature," Latin American Journal of Solids and Structures, vol. 15 , no. $1,2018$.

[23] Y. T. Chien, R. Hamid, and M. Kasmuri, "Dynamic stressstrain behaviour of steel fiber reinforced high-performance concrete with fly ash," Advances in Civil Engineering, vol. 2012, Article ID 907431, 6 pages, 2012.

[24] J. L. Tao, Y. Z. Chen, and C. J. Tian, "Analysis of the inertial effect of the cylindrical specimen in SHPB system," Acta Mechanica Solida Sinica, vol. 26, no. 1, pp. 107-110, 2005.

[25] Q. Ping, M. J. Wu, P. Yuan et al., "Experimental study on dynamic mechanical properties of high temperature sandstone under impact loads," Chinese Journal of Rock Mechanics and Engineering, vol. 38, pp. 782-792, 2019.

[26] W. Z. Zhong, A. Rusine, T. Jankowiak et al., "Influence of interfacial friction and specimen configuration in split Hopkinson pressure bar system," Tribology International, vol. 90, pp. 1-14, 2015.

[27] L. Song and S. S. Hu, "Two-wave and three-wave method in SHPB data processing," Explosion and Shock Waves, vol. 25, no. 4 , pp. $368-373,2005$. 